TECHNICAL NOTE

\title{
IMPLEMENTATION OF THE STRUCTURAL PERFORMANCE FACTOR (SP) WITHIN A DISPLACEMENT-BASED DESIGN FRAMEWORK
}

\author{
Dion Marriott ${ }^{1}$
}

(Submitted November 2017; Reviewed April 2018; Accepted May 2018)

\begin{abstract}
This paper discusses the application of the Structural Performance factor ( $\mathrm{S}$ ) within a Direct DisplacementBased Design framework (Direct-DBD). As stated within the New Zealand loadings standard, NZS1170.5:2004 [1], the SP factor is a base shear multiplier (reduction factor) for ductile structures, i.e. as the design ductility increases, the $S_{P}$ factor reduces. The $S_{P}$ factor is intended to acknowledge the better-thanexpected structural behaviour of ductile systems (both strength, and ductility capacity) by accounting for attributes of response that designers are unable to reliably estimate. The $S_{P}$ factor also recognizes the less dependable seismic performance of non-ductile structures, by permitting less of a reduction (a larger $S_{P}$ factor) for non-ductile structures. Within a traditional force-based design framework the $S_{P}$ factor can be applied to either the design response spectrum (a seismic hazard/demand multiplier), or as a base shear multiplier at the end of design (structural capacity multiplier) - either of these two approaches will yield an identical design in terms of the required design base shear and computed ULS displacement/drift demands. However, these two approaches yield very different outcomes within a Direct-DBD framework - in particular, if $S_{P}$ is applied to the seismic demand, the design base shear is effectively multiplied by $\left(S_{P}\right)^{2}$ (i.e. a two-fold reduction). This paper presents a "DBD-corrected" $S_{P}$ factor to be applied to the design response spectrum in Direct-DBD in order to achieve the intent of the $S_{P}$ factor as it applies to force-based design. The proposed DBD-corrected Sp factor is attractive in that it is identical to the Sp relationship applied to the elastic site hazard spectrum $\mathrm{C}(\mathrm{T})$ for numerical integration time history method of analysis within NZS 1170.5:2004 $[1], \mathrm{SP}, \mathrm{DDBD}=(1+\mathrm{SP}) / 2$.
\end{abstract}

\section{INTRODUCTION}

The $S_{P}$ factor was first introduced within the 1992 loadings standard NZS4203:1992 [2] and later carried over into the seismic loading provisions of NZS1170.5:2004 [1]. It was also carried over to the NZSEE seismic evaluation and retrofit guidelines [3], and the more recent NZSEE seismic assessment guidelines [4].

The $S_{p}$ factor is currently included within the current NZ Bridge Manual [5] for the design of bridge structures, where the focus of this document is on elastic force-based design methods (Equivalent Static Force Analysis, and Modal Response Spectrum Analysis). Chapter 5 of this document discusses future developments of this manual, which may include Displacement-Based Design (DBD) - it appears that the 20102011 Canterbury earthquakes delayed this work. When DBD is implemented into the NZ Bridge Manual, implementation of the $S_{P}$ factor into the design procedures will be a necessary step (unless $\mathrm{SP}=1.0$ is adopted).

The author also understands that $\mathrm{Sp}$ will be retained within an upcoming NZSEE Seismic Isolation Design Guide for seismically isolated structures (Personal communication: NZSEE Study Group). Exactly how $S_{P}$ will be implemented in this document will not be entirely realized until a draft, or final, document is publically released.

In essence, the $S_{P}$ factor is an additional force reduction factor for ductile structures. There are many compelling reasons for the adoption of the $S_{P}$ factor in literature, although not all of them appear to be supported by technical studies. The commentary to the New Zealand loadings standard NZS1170.5:2004 [6] (Section C4.4) discusses a number of technical reasons behind the $S_{P}$ factor, but the general concept in the loadings standard is that a ductile structure has more dependable performance than a non-ductile structure, and thus a greater force reduction factor is permitted for ductile structures (or any structure in which ductile detailing is provided, regardless of the design ductility factor for which they are designed for). The commentary also states that the $S_{P}$ factor is intended to account for inherent conservatism in design methods, and favourable attributes of structural response and behaviour that designers are unable to reliably estimate, such as:

- Individual elements are typically stronger than predicted in design due to strain hardening, expected material strengths, etc

- The total structural capacity is typically greater than predicted due to secondary gravity elements, structural redundancy etc

- The energy dissipation is typically greater than assumed due to damping from non-structural components and from the foundation system.

King et al [7] also cites the SP factor as being a "nebulous quantity" to account for non-quantifiable aspects of structural 
performance, and that other international codes often amalgamate the structural ductility factor and the inverse of the SP factor into a single force reduction factor (the Response Modification Factor, $R$, in North America [8], for example). It is also reasoned that the $S_{P}$ factor accounts for the underestimation of the actual ductility capacity in design, or that structures will be subjected to ductility demands during an actual earthquake that are significantly less than fully revised cyclic laboratory testing, in which their specific ductile detailing was defined. NZS4203:1992 [2] also cites previous research to justify a reduction in design acceleration (for ductile structures), whereby analytical studies on linear elastic SDOF systems showed that the "average" maximum peak acceleration that occurred over more than one cycle was less than the absolute peak acceleration that occurred only once throughout a ground motion.

The relationship between SP and structural ductility is defined specifically for each material design standard. In particular, with respect to the Concrete Structures Standard NZS3101:2006 [9] $\mathrm{S}_{\mathrm{P}}=0.7$ is applied to design ductility factors of 3 or more for concrete structures, and for the Steel Structures Standard NZS3404:1997 [10] $S_{P}=0.7$ is applied to Category 1 $\& 2$ steel structures. For simplicity, and for the purposes of this paper, the relationship between $S_{P}$ and structural ductility is defined by NZS1170.5:2004 i.e. $S_{P}=0.7$ for $\mu \geq 2, S_{P}=1.0$ for $\mu \leq 1$, and linear interpolation for $1<\mu<2$.

While the $S_{P}$ factor acts as a base shear multiplier (force reduction factor), it also indirectly acts to reduce the (ULS) design displacement by the same proportion as shown in Figure 1. This is because NZS1170.5:2004 [1] requires that the lateral displacements associated with seismic design forces which include $\mathrm{S}_{\mathrm{P}}$ are multiplied by the design ductility factor only (or more specifically $\mathrm{k}_{\mu}$ ) and are not further increased by $1 / \mathrm{SP}_{\mathrm{P}}$. Thus, the $\mathrm{S}_{\mathrm{P}}$ factor reduces both the design strength, and design displacements imposed on the lateral structure. The discussion on $S_{P}$ as it relates to seismic design in this paper is limited to $S_{P}$ as it applies to the design of the primary lateral system in a Displacement-Based Design framework. Aspects of $S_{P}$ as they relate to amplified ULS displacement demands imposed on critical non-structural elements (in combination with $S_{P}=1.0$ ) in accordance with the September 2016 amendment to NZS1170.5:2004 [11], are not considered.

Current New Zealand design and assessment standards/guidelines do not currently adopt $\mathrm{SP}_{\mathrm{P}}$ with sufficient consistency to be used within a Direct Displacement-Based Design (DDBD) framework (without modification to $\mathrm{SP}$ ). This paper provides a consistent approach for the adoption of $S_{P}$ into a DDBD framework.

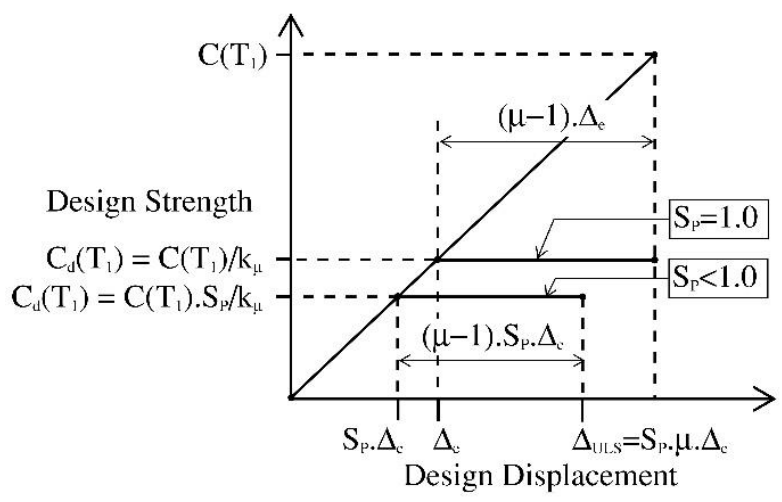

Figure 1: Structural performance factor, SP as applied to force-based design in NZS1170.5:2004.
The Role of the Structural Performance Factor in ForceBased Design

It should be appreciated that the $\mathrm{S}_{\mathrm{P}}$ factor is a multiplier (forcereduction factor) specific to FBD. The primary design output of FBD is the Design Base Shear ( $\mathrm{V}_{\text {Base}}$ ) of a structure. According to FBD, the Design Base Shear coefficient (for an equivalent SDOF system) is related to the fundamental period of the structure (which includes the effective mass, stiffness, and any soil flexibility dependency), and the structural ductility factor (which should also be verified by estimating the yield displacement of the structure). Furthermore, lateral displacements are a bi-product of design in FBD, and depend on the fundamental period of the structure (and the seismic hazard). That is, while the design may be iterative in order to control displacements, displacements are computed at the end of design. These aspects of FBD are important to note because it is for these reasons that the design is unaffected by the method of application of the $S_{P}$ factor - that is, there is no difference in design strength (design base shear) regardless of whether the elastic response spectrum is multiplied by $S_{P}$, or whether the $S_{P}$ factor is applied as a base shear multiplier (and as a ULS displacement multiplier) at the end of design.

\section{The Impact of the Structural Performance Factor in Displacement-Based Design}

Technically, within a Direct Displacement-Based Design framework (referred to as Direct-DBD), the $S_{P}$ factor should be equal to 1.0 - the elastic spectral ordinates (5\% damped, typically) are reduced by the damping-ductility relationships inherent within the Direct-DBD procedure, and require no further reduction. However, as stated previously, the $S_{P}$ factor made its way into the Direct-DBD evaluation and assessment procedure contained within the NZSEE design and assessment guidelines [3,4]. In particular, Section 5.6 of the 2006 guidelines [3] and C3.10.2 of the 2017 guidelines [4] state that the $S_{P}$ factor can be used to reduce the demand spectral ordinates (seismic hazard), or can be used to enhance the estimated lateral capacity: these two procedures will yield different results in Direct-DBD. The impact of the $S_{P}$ factor in Direct-DBD, as applied to the seismic hazard, can be explained via Figure 2 below.

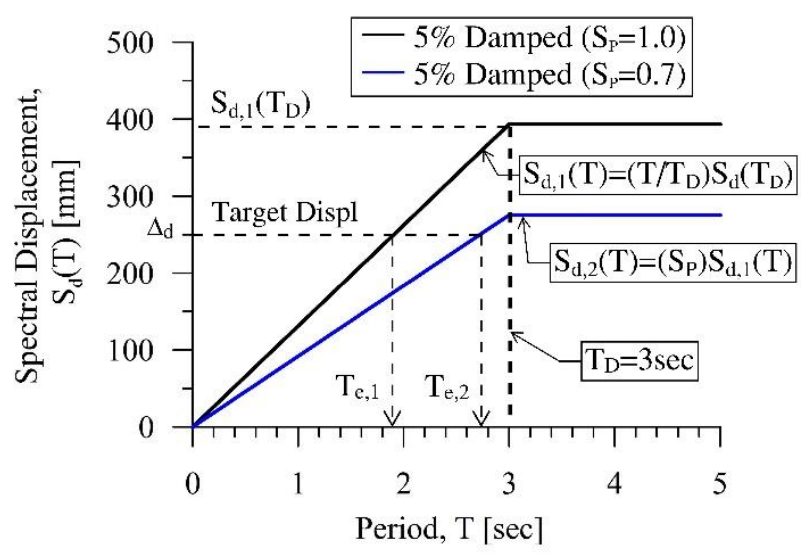

Figure 2: Elastic (linearised) design spectrum to illustrate the relationship between $S_{P}$ and the effective period in design $(z=0.4, R=1.0, D>20 k m$, Soil Cat C).

Figure 2 shows two design displacement spectra $\left(S_{d, 1}\right.$ and $\left.S_{d, 2}\right)$, which have been linearised out to the displacement corner period $\left(T_{D}=3.0 \mathrm{sec}\right)$. The effects of a linearised displacement spectrum are discussed later. For the purpose of this example the lower spectrum $\left(\mathrm{S}_{\mathrm{d}, 2}(\mathrm{~T})\right)$ is equal to the higher spectrum $\left(\mathrm{S}_{\mathrm{d}, 1}(\mathrm{~T})\right)$ multiplied by $S_{P}$ i.e. $\mathrm{S}_{\mathrm{d}, 2}(\mathrm{~T}) / \mathrm{S}_{\mathrm{d}, 1}(\mathrm{~T})=\mathrm{S}_{\mathrm{P}}$. For a given target displacement $\left(\Delta_{d}\right)$, the ratio of effective periods $\left(T_{e}, 1\right.$ and 
$\mathrm{T}_{\mathrm{e}, 2)}$ are (linearly) proportional to the ratio of the seismic hazard i.e. $T_{e}, 1 / T_{e}, 2=S_{P}$. The effects of a non-linear displacement spectrum are discussed later in this paper.

In order to define the design strength for the two systems in Figure 2, the Direct-DBD base shear is given by Equation 1 below,

$$
V_{b}=K_{e} \cdot \Delta_{d}
$$

where $K_{e}$ is the effective (secant) stiffness of the structure, and $\Delta_{d}$ is the (design) target displacement.

Through substitution of the linear seismic hazard into Equation 1, the base shear can be expressed as Equation 2 as follows,

$$
V_{b}=(2 \pi)^{2} \cdot \frac{m_{e}}{\Delta_{d}} \cdot\left(\frac{S_{d}\left(T_{D}\right)}{T_{D}}\right)^{2}
$$

where $V_{b}$ is the design strength, $m_{e}$ is the effective mass, $T_{D}$ is the corner period defining the displacement plateau on the design response spectrum, and $S_{d}\left(T_{D}\right)$ is the spectral displacement at $T_{D}$.

From Equation 2 it is clear that the design strength is proportional to the seismic hazard squared. Thus, the ratio between the design strength of the two systems is given by Equation 3,

$$
\frac{V_{b, 2}}{V_{b, 1}}=\left(S_{P}\right)^{2}
$$

where $\mathrm{V}_{\mathrm{b}, 1}$ and $\mathrm{V}_{\mathrm{b}, 2}$ is the design strength of system 1 and system 2 respectively. Thus, a $S_{P}$ factor of 0.7 results in an effective base shear multiplier equal to $0.49\left(S_{P}=0.7^{2}\right)$ when applied directly to the design displacement spectrum. This relationship between the design base shear and the seismic hazard has been previously discussed in detail elsewhere $[12,13]$.

For situations where the displacement response spectrum is non-linear, i.e. when the near-fault factor is included $\mathrm{N}(\mathrm{T}, \mathrm{D})>1.0$, or where a site specific response spectrum is available, the design base shear may no longer be proportional to the seismic hazard squared. It is worth noting that over the constant displacement region of the design spectrum $\left(T>T_{D}\right.$, when $\mathrm{N}(\mathrm{T}, \mathrm{D})=1.0$ ) there is no unique design solution for Direct$\mathrm{DBD}$, as the effective period has no unique displacement ordinate. Two common approaches adopted in design are to either reduce the effective period to at least equal the corner period $\left(T_{D}\right)$, or extrapolate the design displacement spectrum beyond $\left(T_{D}\right)$ based on the procedure discussed in the following section.

\section{The Design Displacement Spectrum}

Unless the designer is presented with a site-specific design displacement spectrum, the design acceleration spectrum is typically used to derive a design displacement response spectrum for use in Direct-DBD (via double integration of the acceleration response spectrum).

The relationships adopted in NZS1170.5 [1] to define the elastic acceleration response spectrum results in a near-linear design displacement response spectrum for periods less than the displacement corner period of $T_{D}=3.0 \mathrm{sec}$ (in fact, for periods less than $1.5 \mathrm{sec}$, a linear displacement response is approximate only, but sufficient for design). For periods greater than $\mathrm{T}_{\mathrm{D}}$, the acceleration response spectrum is a function of $1 / \mathrm{T}^{2}$, resulting in a displacement plateau for $\mathrm{T}>\mathrm{T}_{\mathrm{D}}$. More specifically, the corner period $\mathrm{T}_{\mathrm{D}}$ corresponds to the transition from constant velocity to constant displacement. For sites defined as a nearfault region located within $20 \mathrm{~km}$ of a known active fault $(\mathrm{D}<20 \mathrm{~km}$, and $\mathrm{N}(\mathrm{D}, \mathrm{T})>1.0)$ the transition to the constant displacement plateau is pushed out to $\mathrm{T}=5.0 \mathrm{sec}$, and the displacement response spectrum is characterised by a series of nonlinear segments up to $T=5.0 \mathrm{sec}$. In effect, the near-fault factor removes the constant velocity region of the design spectrum, resulting in a nonlinear design displacement spectrum.

The design displacement spectrum can be defined directly from the design acceleration spectrum by one of two methods. The first method (Spectrum A) is to define the design displacement spectrum at every period ordinate using Equation 4, while the second method (Spectrum B) defines the design displacement spectrum as a linear relationship with respect to the displacement corner period (TD) given by Equation 5. For both methods the recommendation is that the design spectrum be linearly extrapolated beyond the displacement corner period (TD); see also Sullivan et al [14]. Hence, Spectrum A would be generated using Equation 4 and Equation 5 below, while Spectrum B would be generated using only Equation 5 for all periods. The two spectra are illustrated graphically in Figure 3.

For $\mathrm{T}<\mathrm{T}_{\mathrm{D}}$

$$
S_{d}(T)=\left(\frac{2 \pi}{T}\right)^{2} \cdot S_{a}(T) \cdot g
$$

For $\mathrm{T}>\mathrm{T}_{\mathrm{D}}$

$$
S_{d}(T)=\frac{T}{T_{D}} \cdot\left[\left(\frac{2 \pi}{T_{D}}\right)^{2} \cdot S_{a}\left(T_{D}\right) \cdot g\right]
$$

where $S_{a}(T)$ is the spectral acceleration at period $T$ defined by NZS1170.5:2004 [1], and $g$ is gravity.

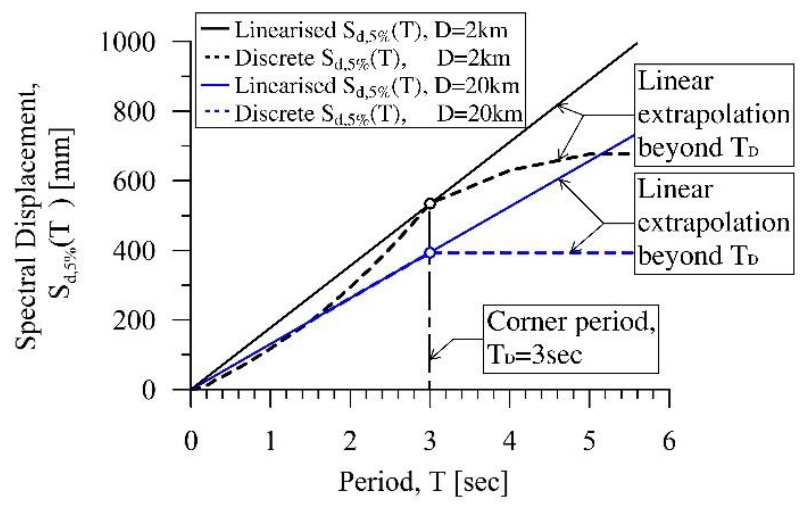

Figure 3: Linearized versus Discrete displacement spectrum, including linear extrapolation beyond the displacement corner period (TD) with and without the full near-fault factor $(z=0.4, R=1.0, D=20 \mathrm{~km} \& D=2 \mathrm{~km}$, Soil Cat $C)$.

At the time of writing this paper, the author understands that the NZS1170.5:2004 [1] long-period response spectrum is currently being revised for the draft NZSEE Seismic Isolation Design Guidelines (Personal communication: NZSEE Study Group). The design of seismically isolated structures typically follows a displacement-based design process. In particular, the revision for the guidelines may lead to an increase to the period which defines the transition from constant velocity to constant displacement (i.e. the displacement corner period, $\mathrm{T}_{\mathrm{D}}$ ). Increasing the displacement corner period is analogous to linear extrapolation of the displacement response spectrum beyond $\mathrm{T}_{\mathrm{D}}$ when the near-fault factor is equal to one, i.e. $\mathrm{N}(\mathrm{D}, \mathrm{T})=1.0$. 

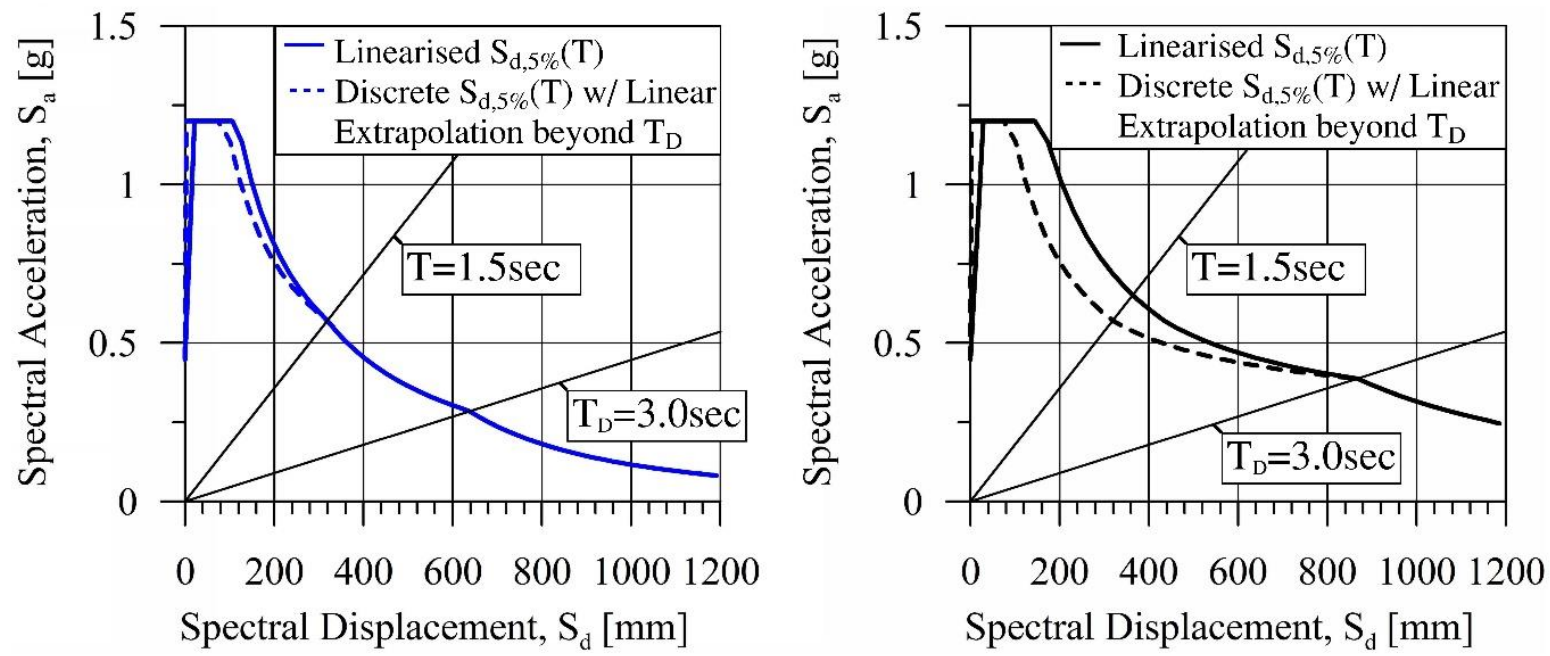

Figure 4: Linearized versus discrete acceleration-displacement response spectrum, $(z=0.4, R=1.0$, Soil cat C). Left: $D>20 \mathrm{~km}$,
\[ N(D, T)=1.0, \text { Right: } D<2 \mathrm{~km}, N(D, T) \geq 1.0 . \]

While the linearised displacement spectrum (Spectrum B) is often sufficiently accurate for the purposes of Direct-DBD, the discrete displacement spectrum (Spectrum A) can be useful when using Direct-DBD for the seismic assessment and retrofit of existing structures in combination with the AccelerationDisplacement Response Spectrum (ADRS). Existing structures are more likely to have lower displacement ductility capacities, and thus lower effective periods than that of a new structure, and would be more likely to be effected by any differences between the two design spectra.

To illustrate this, Figure 4 compares Spectrum A and B within the acceleration-displacement domain. For far-field sites $(\mathrm{N}(\mathrm{D}, \mathrm{T})=1.0)$, for all periods, the difference between the two spectra is negligible, and the linearised displacement spectrum (Spectrum B) will be sufficiently accurate for design of most new and existing structures. For near-fault sites $(\mathrm{N}(\mathrm{D}, \mathrm{T})>1.0)$, the difference between the two spectra is more pronounced, specifically for periods less than $T_{D}=3.0 \mathrm{sec}$, which is likely to be more of an issue for evaluation and retrofit of existing buildings, but could also influence the new design of structures with short effective periods.

\section{Current Application of the SP-Factor in Design}

As previously mentioned, in FBD the $\mathrm{S}_{\mathrm{P}}$ factor can be applied to either the design response spectrum, or to the design base shear (and ULS displacement) at the end of design, with an identical outcome in terms of design forces and design displacements. Similarly, for the seismic assessment and retrofit using FBD, either the design acceleration spectrum can be reduced by $\mathrm{SP}_{\mathrm{P}}$, or the capacity (strength) of the structure can be increased by $1 / \mathrm{S}$, and will result in an identical outcome.

In Direct-DBD it is not correct to apply the $S_{P}$ factor to either the design response spectrum, or to the design base shear, as these two methods are not equivalent. In order to apply an $S_{P}$ factor to the design response spectrum in Direct-DBD, and arrive at an equivalent performance that would be achieved if SP were applied to the design strength at the end of design, a modified form of $S_{P}$ is required. If the design displacement spectrum is linear, the modified form of $S_{P}$ would be given by Equation 6:

$$
S_{P, D D B D}=\sqrt{S_{P}}
$$

where $S_{P, D D B D}$ is the "Direct-DBD corrected" form of $S_{P}$ as applied to the design displacement spectrum. Figure 5 graphically illustrates the difference in design when $S_{P}$ is applied as a design strength multiplier (using $S_{P}$ ) when compared to applying $S_{P}$ to the design response spectrum (using $\mathrm{S}_{\mathrm{P}, \mathrm{DDBD}}$ ). Note that in Figure $5 \mathrm{a}, \mathrm{S}_{\mathrm{P}}$ is only applied to the base shear, and not the lateral displacement. Furthermore, the yield displacement is independent of the lateral strength of the system. Figure 5 is a complete example for a system having an effective period $\left(\mathrm{T}_{\mathrm{e}}\right)$ of 2.5 seconds, and a displacement ductility $(\mu)$ of 4 (all other parameters are summarised in the caption of the figure). Figure $5 \mathrm{~b}$ illustrates that an equivalent $S_{P, D D B D}$ spectral multiplier of $(0.7) 0.5=0.84$ is required to achieve the same design strength (and lateral displacement) for an equivalent design adopting a base shear multiplier of $\mathrm{S}_{\mathrm{P}}=0.7$. When working within the ADRS domain, a more transparent design is achieved when $S_{P, D D B D}$ is applied to the design response spectrum as the intersection of the capacity and demand ordinates intersect. While it is the author's preference that $S_{P}$ be applied to the design response spectrum (using $\left.S_{P, D D B D}\right)$, both methods are equivalent. However, Equation 6 may not be valid if the design displacement spectrum is nonlinear.

\section{THE DEVELOPMENT OF A DIRECT-DBD CORRECTED SP FACTOR}

As previously discussed, when $S_{P}$ is applied to the design response spectrum the reduction in base shear is proportional to $\mathrm{SP}_{\mathrm{P}}$ squared in Direct-DBD when the displacement spectrum is linear i.e. constant pseudo-spectral velocity. The Sp-squared relationship does not apply to a non-linear design displacement spectrum. An equivalent Direct-DBD corrected $S_{P}$ factor (defined as S S,DDBD) for use with the NZS1170.5:2004 [1] design spectrum is presented herein. The $S_{P, D D B D}$ factor was determined by back-calculating the spectral multiplier ( $\mathrm{S}_{\mathrm{P}, \mathrm{DDBD}}$ ) that was required to achieve the same design strength if $S_{P}$ were applied at the end of design as a base shear multiplier. This exercise was performed for Soil Category A though to E, with or without the full near-fault factor $(\mathrm{N}(\mathrm{D}, \mathrm{T}))$, and for a structural ductility of $\mu=1.25-6$. Consideration of all site soil classes was considered for completeness as the period ordinate that defines the end of the constant acceleration plateau is a function of Site Soil Class. 


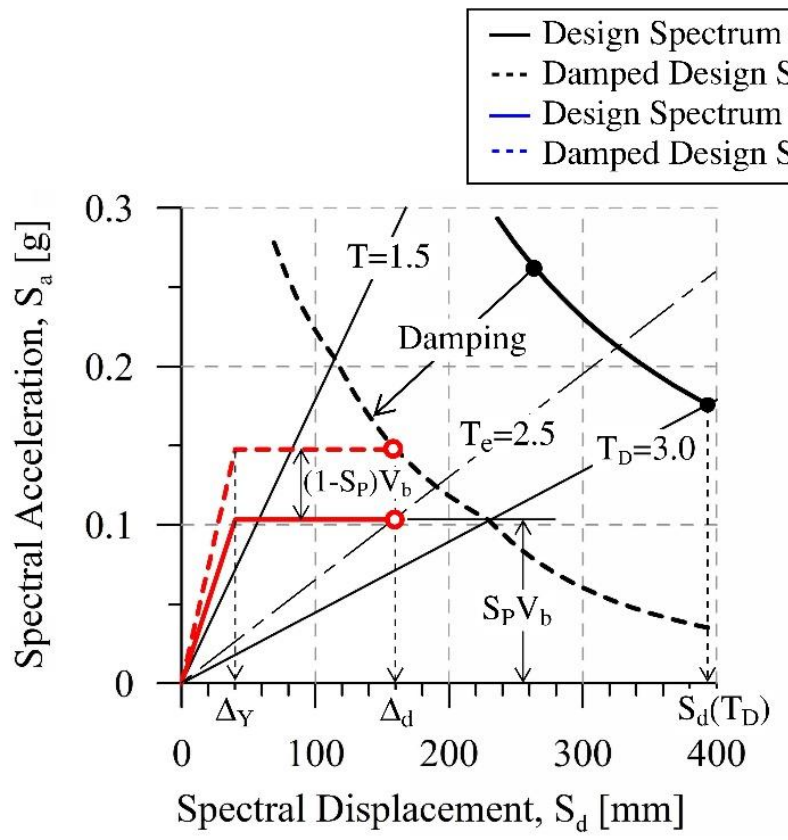

a) Base shear reduction method

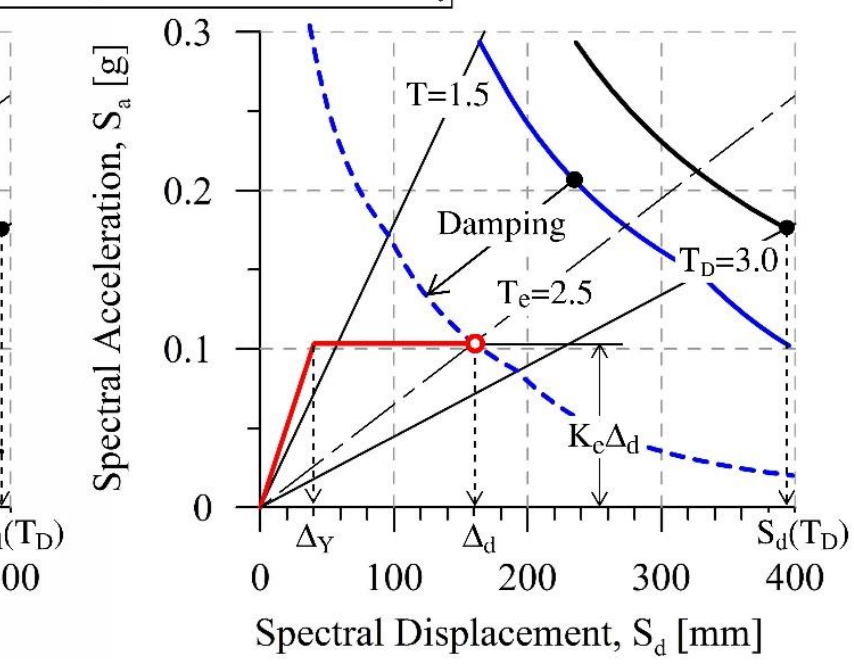

b) Spectrum reduction method

Figure 5: DDBD design comparison using ADRS $(z=0.4, R=1.0$, Soil Cat $C, D=20 \mathrm{~km}, \Delta d=161 \mathrm{~mm}, \Delta y=40 \mathrm{~mm}, \mu=4.0$, $\left.\xi_{e q}=18.5 \%, R_{\xi}=0.59, S_{P}=0.7, S P, D D B D=0.84, S P V b / W_{t}=0.103\right)$.

Table 1 below summarises the calculations for one system having an effective period $\left(\mathrm{T}_{\mathrm{e}}\right)$ of 2.5 seconds, and a structural ductility of $\mu=4.0$ (this is the same system presented graphically in Figure 5).

When this back-calculating exercise is repeated for an effective period range of $0.5-6.0$ seconds, the resulting spectrum multiplier $\left(\mathrm{S}_{\mathrm{P}, \mathrm{DDBD}}\right.$ ) is plotted in Figure 6. In particular, Figure 6a plots the $S_{P-D D B D}$ multiplier, as applied to the elastic design spectrum, required to achieve an equivalent $S_{P}=0.7(\mu>2)$ and $\mathrm{SP}_{\mathrm{P}}=0.925(\mu=1.25)$ base shear multiplier for far-field seismicity $(\mathrm{D}>20 \mathrm{~km}, \mathrm{~N}(\mathrm{~T}, \mathrm{D})=1.0)$ on Site Soil Class A through
C. Figure $6 \mathrm{~b}$ plots this same relationship for near-fault seismicity $(D<2 \mathrm{~km}, \mathrm{~N}(\mathrm{~T}, \mathrm{D}) \geq 1.0)$. Figures $6 \mathrm{c}$ and $6 \mathrm{~d}$ plot the same relationships for Site Soil Class D and E (Soil Class D and $\mathrm{E}$ are equivalent, with the exception of one period ordinate $(\mathrm{T}=1.0 \mathrm{sec}))$.

For all site soil classes, the required spectral multiplier $S_{P, D D B D}$ converges to $\left(\mathrm{S}_{\mathrm{P}}\right)^{0.5}$ for periods greater than 1.5 seconds, for farfield sites (due to the linear displacement spectrum relationship beyond $\mathrm{T}=1.5$ seconds). Similarly, for all site soil classes, the required spectral multiplier $S_{P, D D B D}$ converges to $\left(\mathrm{S}_{\mathrm{P}}\right)^{0.5}$ for periods greater than 3.0 seconds for near-fault sites (due to the linear extrapolation beyond $\left.\mathrm{T}_{\mathrm{D}}\right)$. The filled-in symbols in Figure

Table 1: Summary of system parameters for $T_{e}=2.5 \mathrm{sec}$ example $(z=0.4, R=1.0, D=20 \mathrm{~km}, N(T, D)=1.0$, soil category $C$ : displacement corner period 3.0sec $\left(T_{D}\right)$, effective mass 180 tonne).

\begin{tabular}{|c|c|c|}
\hline \multicolumn{2}{|c|}{ Design Spectral Displacement at $T_{D}$, and Design Ductility } & $\mathrm{S}_{\mathrm{d}}\left(\mathrm{T}_{\mathrm{D}}, 5 \%\right)=394 \mathrm{~mm}, \mu=4.0$ \\
\hline \multicolumn{2}{|c|}{ Equivalent Viscous Damping, and Spectral Multiplier } & $\xi_{\mathrm{eq}}=18.5 \%, \mathrm{R}_{\xi}=0.59($ Sullivan et al 2012$)$ \\
\hline \multicolumn{2}{|c|}{ Damped Spectral Displacement at $T_{D}$} & $\mathrm{~S}_{\mathrm{d}}\left(\mathrm{T}_{\mathrm{D}}, 5 \%\right) \cdot \mathrm{R}_{\xi}=232 \mathrm{~mm}$ \\
\hline & \multicolumn{2}{|r|}{ Method of Sp Application } \\
\hline & Spectrum Reduction Method & Base Shear Reduction Method \\
\hline SP-Factor & $\mathrm{S}_{\mathrm{P}, \mathrm{DDBD}}=0.84$ & $\mathrm{SP}_{\mathrm{P}}=0.7$ \\
\hline Effective Period (target) & $\mathrm{T}_{\mathrm{e}}=2.50 \mathrm{sec}$ & $\mathrm{T}_{\mathrm{e}}=2.50 \mathrm{sec}$ \\
\hline \multirow[t]{2}{*}{ Effective Stiffness } & $\mathrm{Ke}=1137 \mathrm{kN} / \mathrm{m}$ & $\mathrm{Ke}=1137 \mathrm{kN} / \mathrm{m}$ \\
\hline & Pre-SP Stiffness \& Period $\rightarrow$ & $\begin{array}{l}\mathrm{K}_{\mathrm{e}} / \mathrm{SP}=1624 \mathrm{kN} / \mathrm{m} \\
\mathrm{T}_{\mathrm{e}, \mathrm{SP}}=2.09 \mathrm{sec}\end{array}$ \\
\hline Design Displacement & $\Delta_{\mathrm{d}}=160 \mathrm{~mm}$ & $\Delta_{\mathrm{d}}=160 \mathrm{~mm}$ \\
\hline Base Shear & $\mathrm{K}_{\mathrm{e}} \Delta_{\mathrm{d}}=182 \mathrm{kN}$ & $\mathrm{S}_{\mathrm{P}} \mathrm{V}_{\mathrm{b}}=\mathrm{K}_{\mathrm{e}} \Delta_{\mathrm{d}}=182 \mathrm{kN}$ \\
\hline
\end{tabular}


6 represent the spectrum multiplier considering the discrete displacement spectrum (Spectrum A), while the unfilled symbols apply to the linearised displacement spectrum (Spectrum B). As expected, the linearised displacement spectrum results in a design spectrum multiplier of $\left(\mathrm{S}_{\mathrm{P}}\right)^{0.5}$ for all periods, and all site soil classes.

Figure 6 also compares the "exact" $S_{P, D D B D}$ multiplier against a less exact value of $\left(1+\mathrm{S}_{\mathrm{P}}\right) / 2 .\left(1+\mathrm{S}_{\mathrm{P}}\right) / 2$ is the same multiplier that is applied to the target acceleration response spectrum when scaling ground motions for use in numerical integration time history analysis per NZS1170.5:2004. An identical spectrum multiplier for use in both numerical integration time history and Direct-DBD is desirable for design consistency.

Figure 6 suggests that a spectrum multiplier of $(1+\mathrm{SP}) / 2$ would be slightly conservative (with respect to the "exact" SP,DDBD multiplier) for Direct-DBD designs having effective periods equal to, or less than, 1.5 seconds for all site soil classes classified as far-field sites, and also conservative for effective periods equal to, or less than, 3.0 seconds for all site soil classes classified as near-fault sites. Conversely, an unmodified spectrum multiplier equal to $\mathrm{S}_{\mathrm{P}}$ (with no DDBD modification) is, in general, non-conservative for all periods, and all site soil classes.

\section{Proposed Sp Factor for use within a Direct-DBD Framework}

Two methods are proposed to correctly implement the $S_{P}$ factor within a Direct-DBD framework, utilising the design displacement spectrum given by either Equation 4 or 5 above.

Method 1: Spectrum Reduction Method (recommended): The elastic design response spectrum is multiplied by Equation 7 below, where $S_{P, D D B D}$ is referred to as a "Direct-DBD corrected" Sp factor.

$S_{P, D D B D}=\left(1+S_{P}\right) / 2$

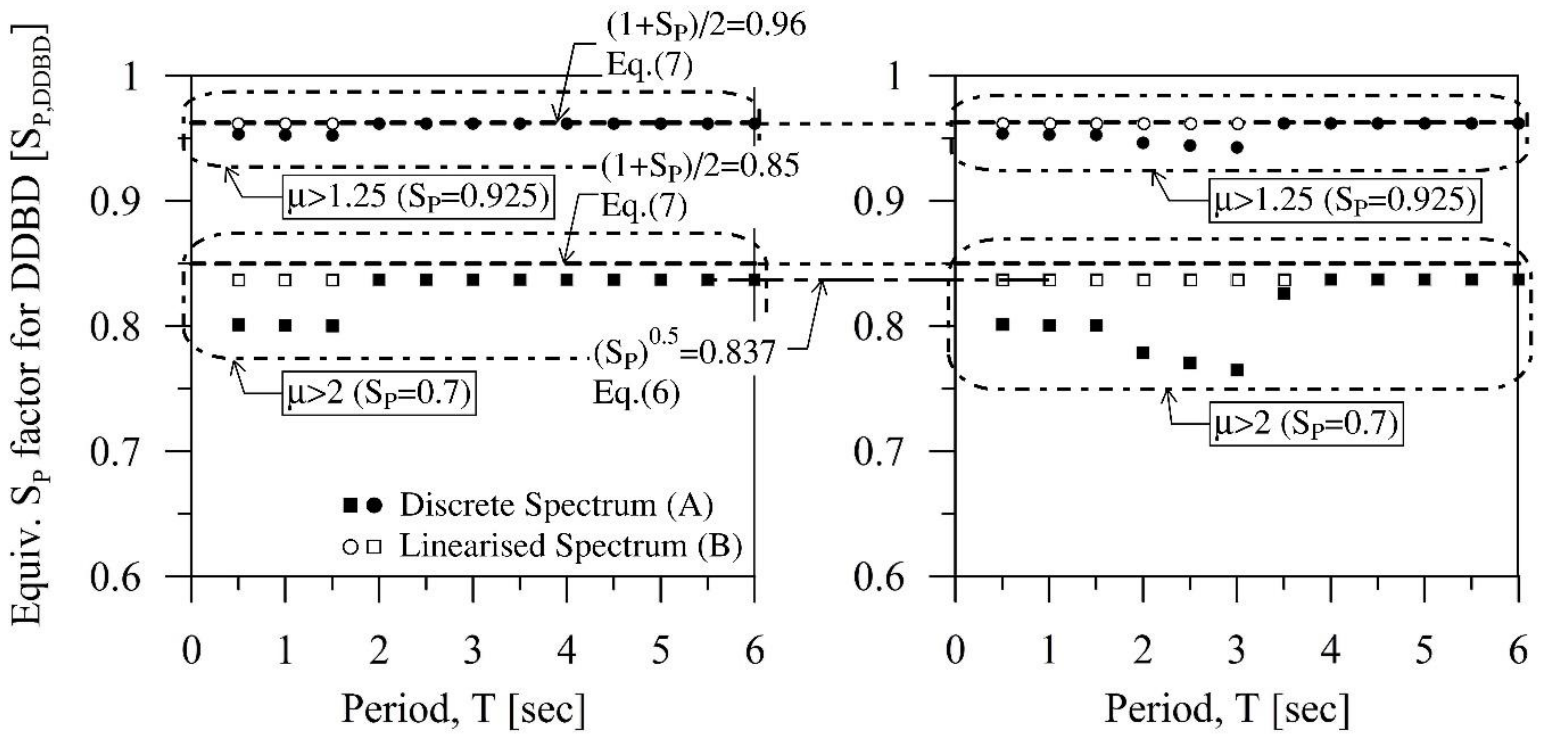

a) Soil category A, B, \& C, far-field hazard $(\mathrm{D}=20 \mathrm{~km})$.

b) Soil category A, B, \& C, near-fault hazard $(\mathrm{D}=2 \mathrm{~km})$

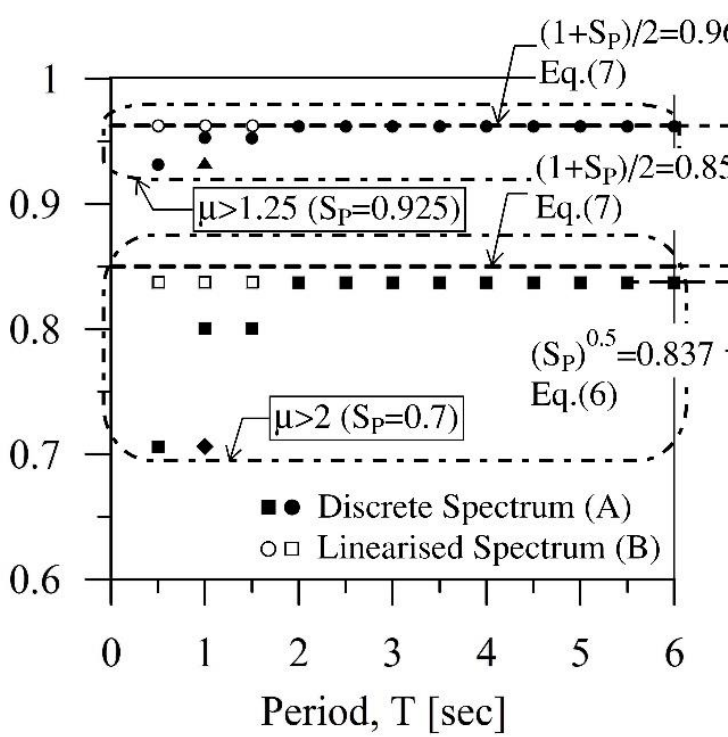

c) Soil category D \& E, far-field hazard $(\mathrm{D}=20 \mathrm{~km})$.

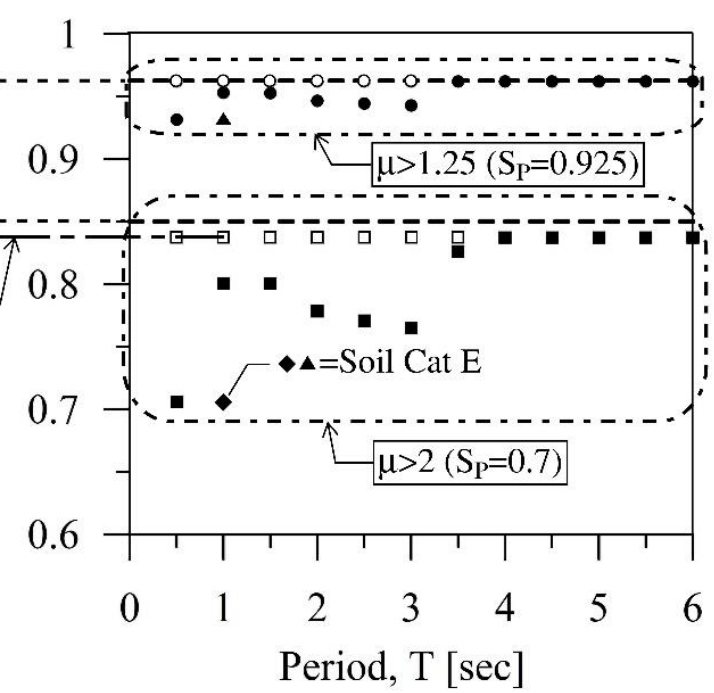

d) Soil category D \& E, near-fault hazard $(\mathrm{D}=2 \mathrm{~km})$

Figure 6: DDBD-corrected SP-factor ( $S P, D D B D)$ for soil category $A, B \& C$ (Soil cat $A=B=C)$. 
Method 1 is the recommended method, as it produces a more transparent design when using the Acceleration-DisplacementResponse-Spectrum (ADRS) in design. The design process for Method 1 is identical for both new design and assessment of existing structures.

Method 2: Base Shear Reduction Method: The elastic design spectrum is first defined with $\mathrm{S}_{P}=1.0$ (no reduction). At the end of design, the base shear is multiplied by $S_{P}$ to define the resultant design base shear (the design displacement spectrum is not multiplied by $S_{\mathrm{P}}$ ). In order to correctly implement this method for the assessment of existing structures, the lateral strength of the structure would by multiplied by $1 / \mathrm{S}$.

\section{CONCLUSIONS}

The implications of the $S_{P}$ factor in Direct-DBD do not appear to have been considered when carried over to the current FBD framework in the New Zealand loadings standard, NZS1170.5:2004 [1], and the NZSEE seismic assessment guidelines. If $S_{P}$ is applied directly to the seismic hazard, without any modification, this paper has shown that the design strength is less than what it should be if applied as a design strength multiplier at the end of design, thus resulting in a nonconservative design. This will potentially result in inconsistent designs from one engineer to the next. This paper presents two methods for correctly implementing the $S_{P}$ factor within a Direct-DBD framework; with the recommended method being to multiply the seismic hazard by a "Direct-DBD corrected" $S_{P}$ factor (termed $\left.S_{P, D D B D}\right)$ equal to $\left(1+\mathrm{S}_{\mathrm{P}}\right) / 2$.

\section{REFERENCES}

1. SNZ (2004). "NZS1 170.5:2004 Structural Design Actions, Part 5: Earthquake Actions". Standards New Zealand, Wellington, NZ.

2. SNZ (1992). "NZS4203:1992 General Structural Design and Design Loadings for Buildings (Loadings Standard)". Standards New Zealand, Wellington, NZ.

3. NZSEE (2006). "Assessment and Improvement of the Structural Performance of Buildings in Earthquakes". New
Zealand Society of Earthquake Engineering, Wellington, NZ.

4. NZSEE (2017). "The Seismic Assessment of Existing Buildings, including March, 2018 Errata. (http://www.eqassess.org.nz/)". New Zealand Society of Earthquake Engineering, Wellington, NZ.

5. NZTA (2016). "Bridge Manual (SP/M/022), Third Edition, Amendment 2". New Zealand Transport Agency, Wellington, NZ.

6. SNZ (2004). "NZS1170.5Supp1:2004 Structural Design Actions, Part 5: Earthquake Actions: Commentary". Standards New Zealand, Wellington, NZ.

7. King AB, Bull DK, McVerry GH and Jury RD (2003). "The Australia/New Zealand Earthquake Loadings Standard, AS/NZS1170.4". 2003 Pacific Conference on Earthquake Engineering, Christchurch, NZ.

8. ASCE (2010). "ASCE7-10 Minimum Design Loads for Buildings and Other Structures". American Society of Civil Engineers, Reston, VA, USA.

9. SNZ (2006). "NZS3101:2006 Concrete Structures Standard, Part 1". Standards New Zealand, Wellington, NZ.

10. SNZ (1997). "NZS3404:1997 Steel Structures Standard, Part 1". Standards New Zealand, Wellington, NZ.

11. SNZ (2016). "NZS1170.5:2004 Structural Design Actions, Part 5: Earthquake Actions (Amendment 1, September 2016)". Standards New Zealand, Wellington, NZ.

12. Priestley MJN (2003). "Myths and Fallacies in Earthquake Engineering, Revisited. Mallet Milne Lecture". IUSS Press, Pavia, Italy.

13. Priestley MJN, Calvi GM and Kowalsky MJ (2007). "Direct Displacement Based Seismic Design of Structures". IUSS Press, Pavia, Italy.

14. Sullivan T, Priestley MJN and Calvi GM (2012). "A Model Code for the Displacement-Based Seismic Design of Structures". IUSS Press, Pavia, Italy. 